\title{
Environmental quality, climate indicators, and COVID-19 pandemic: insights from top 10 most affected states of the USA
}

\author{
Bilal $^{1}$ (D) $\cdot$ Muhammad Farhan Bashir $^{2}$ (D) Khurram Shahzad $^{3} \cdot$ Bushra Komal $^{4} \cdot$ Muhammad Adnan Bashir $^{5} \cdot$ \\ Madiha Bashir ${ }^{6}$. Duojiao Tan ${ }^{1} \cdot$ Tehreem Fatima $^{7} \cdot$ Umar Numan $^{2}$
}

Received: 26 October 2020 / Accepted: 20 January 2021 / Published online: 25 February 2021

(C) The Author(s), under exclusive licence to Springer-Verlag GmbH, DE part of Springer Nature 2021

\begin{abstract}
In the current context of the COVID-19 pandemic, researchers are working with health professionals to inform governments on how to formulate health strategies. In this study, we examine the correlation between environmental and climate indicators and COVID-19 outbreak in the top 10 most affected states of the USA. In doing so, $\mathrm{PM}_{2.5}$, temperature, humidity, environmental quality index, and rainfall are included as crucial meteorological and environmental factors. Kendall and Spearman rank correlation coefficients, quantile regression, and log-linear negative binominal analysis are employed as an estimation strategy. The empirical estimates conclude that temperature, humidity, environmental quality index, $\mathrm{PM}_{2.5}$, and rainfall are significant factors related to the COVID-19 pandemic in the top 10 most affected states of the USA. The empirical findings of the current study would serve as key policy input to mitigate the rapid spread of COVID-19 across the USA.
\end{abstract}

Keywords Coronavirus $\cdot$ COVID-19 $\cdot$ Environmental quality index $\cdot \mathrm{PM}_{2.5} \cdot$ Temperature

\section{Introduction}

The novel coronavirus is a pandemic caused by severe acute respiratory syndrome coronavirus 2 and first reported in Wuhan, China (Sohrabi et al. 2020). Existing literature has

Responsible editor: Lotfi Aleya

Muhammad Farhan Bashir

farhan.paks89@gmail.com

Bilal

bilal@hbue.edu.cn

Khurram Shahzad

Khurrams.khurram@gmail.com

Bushra Komal

bushrakomal@hotmail.com

Muhammad Adnan Bashir

adnanbashir2034@gmail.com

Madiha Bashir

madihacheema16@gmail.com

Duojiao Tan

tanduojiao@hbue.edu.cn

Tehreem Fatima

tehreem.fati44@hotmail.com reported that the COVID-19 is mainly transmitted through respiratory droplets, as well as human-human transmission (Arslan et al. 2021; Huang et al. 2020; Ge et al. 2013), and its rapid spread led to World Health Organization (WHO) declaring it as a pandemic (Fofana et al. 2020; Khan et al.

Umar Numan

umarnuman@csu.edu.cn

1 Accounting School, Hubei University of Economics, Wuhan, China

2 Business School, Central South University, Changsha (410083), Hunan, People's Republic of China

3 Key Laboratory of Resource Biology and Biotechnology in Western China, Ministry of Education, College of Life Sciences, Northwest University, Xi'an, People's Republic of China

4 Business School, University of International Business and Economics, Beijing, China

5 School of Economics, Nankai University, Tianjin, People's Republic of China

6 Education Department, Government of The Punjab, Punjab, Pakistan

7 Asian Demographic Research Institute, Shanghai University, Shanghai 200444, People's Republic of China 
2020). Higher transmissibility of COVID-19, lack of medical facilities, and unstoppable spread have created psychological fear among the general public (Fattorini and Regoli 2020). Like COVID-19, other coronaviruses such as Middle East respiratory syndrome coronavirus (MERS), severe acute respiratory syndrome coronavirus (SARS), and Ebola have caused health emergencies in recent history (Yao et al. 2020). As a consequence, these pandemics caused a large number of deaths, a shortage of medical supplies, and cost billions of dollars to businesses worldwide (Bilal et al. 2021a; Allocati et al. 2016). Recent research shows that several factors including climate and meteorological indicators, i.e., temperature, rainfall, and humidity, affect the spread of COVID-19 (Hemmes et al. 1962). Tan et al. (2005) suggested that the outbreak of SARS in four major cities in China was significantly correlated with temperature resulted in reported cases. Further studies by Iqbal et al. (2020) and Wang et al. (2020) have highlighted that temperature is beneficial to the viral transmission of COVID-19. Although few recent studies contributed to the matter, however, there is still a lack of evidence in the contemporary literature of these indicators and the COVID-19 pandemic. Therefore, it is essential to understand how these meteorological and environmental conditions affect viral outbreaks, such as COVID-19, hence, providing us motivation to analyze the role of environmental and climate variables in the context of COVID-19 spread in the top 10 states of the USA.

The definite diagnosis of COVID-19 ranges between 0 and $60 \%$ and maximum temperature in-between $12.2^{\circ} \mathrm{C}$ and $22.8^{\circ} \mathrm{C}$ contributes most to such diagnosis (Yao et al. 2020). Additionally, a $1^{\circ} \mathrm{C}$ increase in maximum temperature reduces the fatality rate by $7.5 \%$. The living environment is greatly affected by temperature, hence making it one of the key determinants to control the developments of infectious diseases (McMichael et al. 2008). According to current scientific studies, the transmission of infectious diseases is higher at lower temperatures because of the human body's vulnerability at such temperatures (Huang et al. 2020). Therefore, there is a consensus that transmission of COVID-19 may slowdown in the coming months due to the arrival of summer.

In the USA, the Washington State was the first territory to report COVID-19 diagnosis on January 15, 2020 (Burke 2020), and lack of federal and state initiatives resulted in the viral outbreak as the USA currently holds the most number of infections and deaths from COVID-19 (Jung et al. 2020). California, Florida, Texas, and New York are states with the most cases. Similar widespread outbreaks in European and Asian countries such as Italy, South Korea, Spain, and France led to WHO declaring COVID-19 as a global pandemic (Cucinotta and Vanelli 2020). However, the USA and the New York state are the epicenters of the COVID-19 in the world due to the higher number of cases and deaths (Bashir et al. 2020b; Doğan et al. 2020). The extant research contribution has been dedicated to examining the impact of climate indicators such as temperature, humidity, and rainfall. However, the existing research gap suggests that further research is required to provide fresh evidence regarding the combined association between environmental quality and meteorological indicators.

To examine the impact of COVID-19 in the USA, we consider the top 10 states with the most reported cases. The motive behind choosing the top 10 states is the transparency, urbanization, and global economic influence of these top 10 states. Table 1 outlines the top 10 states with most cases and deaths due to COVID-19 in the USA. Furthermore, Figs. 1 and 2 highlight the trend of total cases, daily confirmed cases, total deaths, and daily confirmed deaths from COVID-19 during the timeline of the current research paper.

Data source: Centers for Disease Control and Prevention, USA (October 8, 2020)

\section{Environmental conditions in the USA}

Following World War II, industrial sector of USA witnessed rapid growth (Bashir et al. 2021), which not only improved the living standards and purchasing power of its residents but also resulted in lower air quality across the country (Bashir et al. 2020a). According to the World Health Organization (WHO 2019), every year, 7 million people die from exposure to environmental pollutants and due to environmental pollution at least 360,000 die prematurely in the USA alone (McDonald et al. 2016), which is why it is of considerable significance to study the impact of environmental pollution and the outbreak of COVID-19 in the USA. Although, recent studies point out that lockdown strategies have improved the environmental quality in the USA (Parodi and Liu 2020) as well as across the globe (Sardar et al. 2020); however, unlike current research no other study has investigated the impact of environmental pollution's association with COVID-19 over an extended period. The current study not only addresses this gap in existing literature but also further divides the top 10 states into Southern and Northwestern regions to provide a detailed

Table 1 Top ten US states with COVID-19 infections and deaths

\begin{tabular}{llll}
\hline No. & State & Cases & Deaths \\
\hline 1 & California & 840,322 & 16,251 \\
2 & Texas & 810,689 & 16,622 \\
3 & Florida & 720,117 & 14,766 \\
4 & New York & 471,638 & 32,836 \\
5 & Illinois & 308,990 & 9,100 \\
6 & Georgia & 308,493 & 7,062 \\
7 & Arizona & 221,937 & 5,713 \\
8 & North Carolina & 221,438 & 3,691 \\
9 & New Jersey & 221,438 & 16,147 \\
10 & Tennessee & 202,257 & 2,594 \\
\hline
\end{tabular}


Fig. 1 Total cases and daily confirmed cases - COVID-19

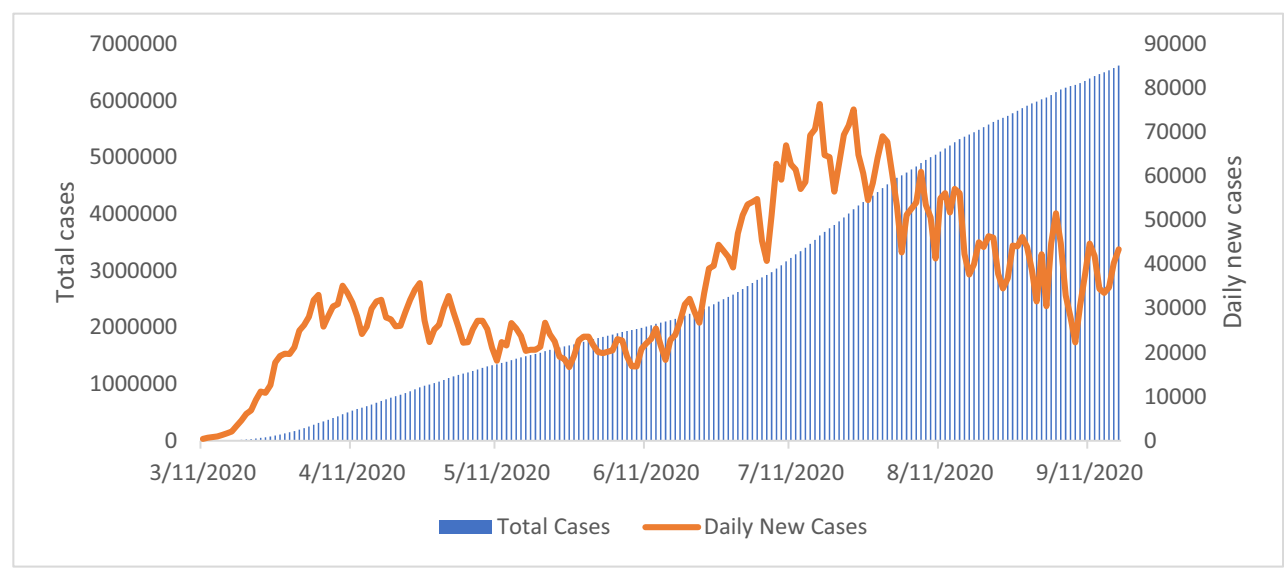

outlook of how meteorological conditions have affected the COVID-19 outbreak in different regions of the USA.

\section{Data and research methodology}

\section{Data specification}

The current research investigates the top 10 most affected states in the USA from March 2, 2020, to September 17, 2020, to provide a detailed outlook of the effects of the COVID-19 pandemic in the USA. The daily new cases, daily new deaths, and total confirmed cases have been included as dependent variables representing COVID-19 during the same period. Temperature is among the crucial meteorological variables, which has been identified as a crucial indicator in spreading COVID-19 (Bashir et al. 2020a, c). We include an average daily temperature in our research as it is of importance to analyze the impact of temperature given several recent studies have provided inconclusive results (Shahzad et al. 2020; Wang et al. 2020). Humidity is another critical factor in COVID-19 transmission, though further scientific explanation is required to create better scientific understanding (Fareed et al. 2020; Wu et al. 2020). The environmental quality index (EQI) examines the impact of environmental pollution and the COVID-19 outbreak in the most affected USA states. Moreover, $\mathrm{PM}_{2.5}$ is included as it exerts a substantial impact on COVID-19 transmission, especially in highly polluted areas (Bashir et al. 2020a, c). Existing literature suggests that higher environmental pollution is responsible for several health issues. Several recent studies have implied that the risk of contracting COVID-19 is significantly higher where the people are exposed to environmental pollutants (Bilal et al. 2021b; Burke et al. 2020; Iqbal et al. 2020). Data for meteorological indicators have been taken from the National weather service, USA; data for environmental and air pollutants (EQI and $\mathrm{PM}_{2.5}$ ) have been taken from the Environmental Pollution Agency (E.P.A.). At the same time, COVID-19 total confirmed cases and deaths have been taken from the Centers for Disease Control and Prevention. The descriptive statistics of the abovementioned variables including their mean values, minimum, maximum values and measures of dispersions is presented in Table 2.
Fig. 2 Total deaths and daily confirmed deaths - COVID-19

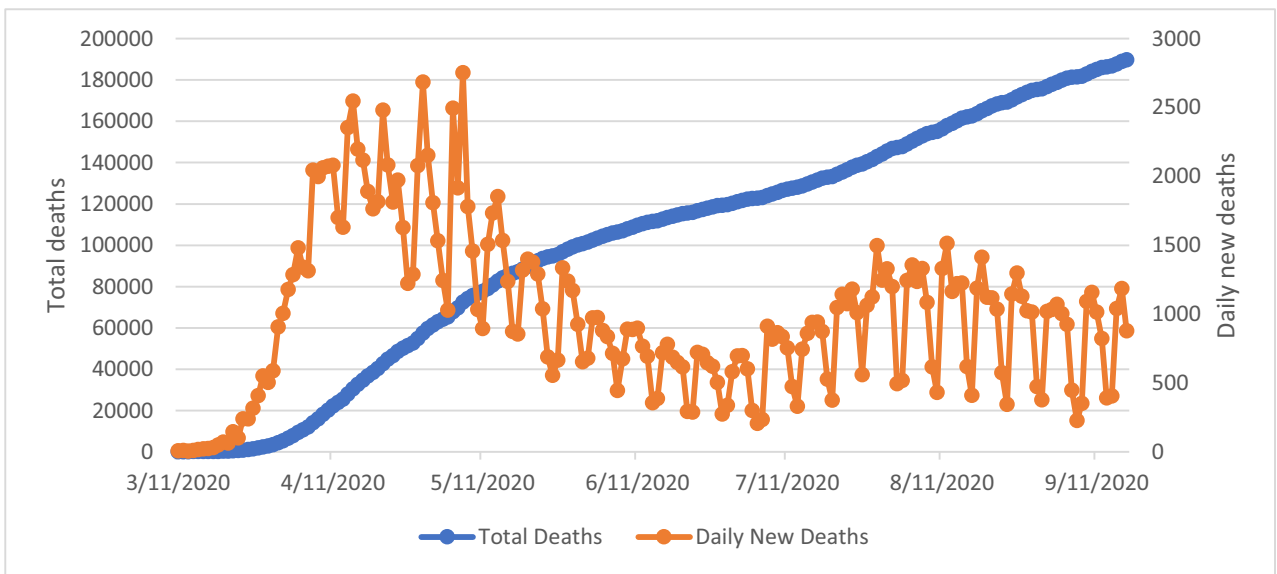


Table 2 Descriptive analysis

\begin{tabular}{llllllllll}
\hline Variables & Obs & Mean & Std. dev. & Min & Max & p1 & p99 & Skew. & Kurt. \\
\hline totaldeaths & 1590 & 4278.161 & 6187.375 & 0.000 & 25196 & 0.000 & 25093 & 2.172 & 7.092 \\
Lndeaths & 1469 & 7.212 & 2.197 & 0.000 & 10.134 & 0.000 & 10.131 & -1.362 & 4.729 \\
newcases & 1590 & 1904.228 & 2540.096 & 0.000 & 15300 & 0.000 & 11126 & 2.242 & 7.817 \\
lnnewcases & 1540 & 6.698 & 1.689 & 0.000 & 9.636 & 0.693 & 9.317 & -1.396 & 5.978 \\
Lntemp & 1590 & 4.372 & 0.196 & 3.526 & 4.762 & 3.807 & 4.700 & -1.007 & 3.817 \\
Lnhum & 1590 & 4.374 & 0.336 & 2.639 & 4.605 & 3.045 & 4.605 & -2.577 & 9.409 \\
lmPM 2.5 & 1590 & 36.000 & 0.405 & 33.000 & 55.000 & 3.958 & 5.740 & 4.567 & 4.950 \\
Lneqim & 1590 & 3.388 & 0.015 & 3.350 & 3.424 & 3.353 & 3.414 & -0.654 & 2.473 \\
Rain & 1590 & 0.117 & 0.356 & 0.000 & 3.21 & 0.000 & 1.940 & 4.685 & 28.894 \\
\hline
\end{tabular}

\section{Estimation strategy}

\section{Kendall and Spearman rank correlation tests}

For empirical analysis, Kendall and Spearman rank correlation tests (Alexander 2008) are used to examine the association between environmental parameters and COVID-19. As a non-parametric test, the spearman rank correlation calculates the strength of the link between two variables and can be estimated through the following:

$\gamma_{s}=\frac{1-6 \times \sum d_{i}^{2}}{n(n 2-1)}$

where the difference between ranks of two parameters and the number of alternatives is represented through $d_{i}$ and $n$ respectively. The empirical values of $\gamma_{s}=-1$ and +1 means a negative and positive correlation respectively.

Kendall rank correlation is the second non-parametric test used by the current study to estimate the ordinal association between two variables, where Kendall's tau $(\tau)$ evaluates the ordering similarity between different datasets through the following formula:

$\mathcal{T}=\frac{[(\text { concor })(\text { discor })]}{0.5 \times n \times(n-1)}$

In Eq. 2, the number of concordant and discordant pairs is represented by concor and discor; the total number of pairs is represented by $n$ and the empirical values between +1 and -1 bear similar interpretation with spearman's correlation.

\section{The negative binomial regression}

We use negative binomial regression as the main analytical tool, which is applied in such a case when the data has several fluctuations, and can reduce any abitalic issues to show the correct impact. Negative binomial regression is part of Poisson regression analytics, where the mean is highlighted by $\theta_{i}$, and is considered as homogenous within the classes. Although classes become heterogeneous if we define a definite distribution for $\theta_{i}$; hence for empirical estimates, we assume that the mean $\theta_{i}$ follows a gamma distribution with mean $\mathrm{E}\left(\theta_{i}\right)=\mu_{i}$ and variance. $\operatorname{Var}\left(\theta_{i}\right)=\mu_{i} v_{i}^{-1}$

Also, negative binomial distribution can be shown through marginal distribution if we assume the Poisson distribution $Z_{i} \mid \theta_{i}$ with a conditional mean $E\left(Z_{i} \mid \theta_{i}\right)=\theta_{i}$. Negative binomial distribution's probability density function can be empirically estimated as:

$$
\begin{gathered}
\operatorname{Pr}\left[Z_{i}=Z_{i}\right]=\Sigma \operatorname{Pr}\left(Z_{i}=Z_{i} \mid \theta_{i}\right) f\left(\theta_{i}\right)^{d} \theta_{i} \\
=\frac{r\left(Z_{i}+V_{l}\right)}{r\left(Z_{i}+V_{l}\right)}\left(\frac{V_{i}}{V_{i}+\mu_{i}}\right)^{V_{i}}\left(\frac{\mu_{i}}{V_{i}+\mu_{i}}\right)^{Z_{i}}
\end{gathered}
$$

where variance parameters can be represented by $\operatorname{VAR}\left(Z_{i}\right)$ $=\mu_{i}+\mu_{i}^{2} V_{i}^{-1} V_{i}$ and mean is $E\left(Z_{i}\right)=\mu_{i} \mathrm{E}\left(\mathrm{Z}_{\mathrm{i}}\right)=\mu_{\mathrm{i}}$.

\section{Quantile regression}

Quantile regression, first developed by Koenker et al. (1978), estimates different regression estimates where each estimator refers to the conditional distribution of different quantiles. The primary difference between OLS and regression analysis is that OLS provides regression coefficients as a consequence where the regression line runs through the average dataset; however, quantile regression provides different quantiles based on data distributions. Such empirical estimations allow us to examine the nature of the relationship between independent and dependent variables over the whole data set, hence providing more comprehensive insights. The mathematical form of the quantile regression model is modeled as follows:

$y_{i}=x^{\prime}{ }_{i} \beta_{\theta}+\mu_{\theta i}, 0<\theta<1$

$\operatorname{Quant}_{\theta}\left(y_{i} / x_{i}\right)=x_{i} \beta_{\theta}$ 
where explanatory variables' vector is represented by $x$; explained variables are represented by $y$; and error term by $\mu$, whose distribution of conditional quantile is equal to zero. The dependent variable's $\theta$ th quantile is $\operatorname{Quant} \theta\left(y_{i} \mid x_{i}\right) ; \widehat{\beta}_{\theta}$ is regression estimator of $\theta$ th quantile and is following formula's solution:

$\min \sum_{y_{i} \geq x_{i}^{\prime} \beta} \theta\left|y_{i}-x_{i} \beta\right|+\sum_{y_{i}<x_{i} \beta}(1-\theta) y_{i}-x_{i}^{\prime} \beta$

\section{Results and discussion}

\section{Correlation analysis}

We applied the Kendall correlation coefficient and Spearman correlation coefficient as an estimating tool for data analysis, and Table 3 presents the results of correlation analysis. For daily new cases, average temperature, humidity, rainfall, and EQI are significant for the Kendall correlation coefficient, while average temperature, $\mathrm{PM}_{2.5}$, EQI, and rainfall are significant for the Spearman correlation test. And daily new deaths from COVID-19, average daily temperature, $\mathrm{PM}_{2.5}$, EQI, and rainfall is significant for the Kendall correlation test and average temperature, humidity, $\mathrm{PM}_{2.5}$, EQI, and rainfall are significant for the Spearman correlation coefficient.

\section{Results of log-linear binomial analysis}

Table 4 provides the empirical estimates of log-linear negative binomial regression to analyze the association between environmental and meteorological indicators and their influence over daily new deaths and daily new cases from most affected regions in the USA. Furthermore, due to significant difference in meteorological conditions, we divide our sample states into the south (Florida, Texas, Georgia, North Carolina, Louisiana) and Northwestern regions (California, Illinois, Arizona, New
Jersey, New York) to create a better understanding of the role of different atmospheric and weather conditions over the COVID-19 outbreak in different geographical locations in the USA (Fig. 3a, b).

The statistical findings suggest that temperature, humidity, $\mathrm{PM}_{2.5}$, EQI, and rainfall are critical determinants in impacting the spread of COVID-19 in the USA. Temperature and humidity have a positive association in daily new cases (model 1), but carry a negative association with daily new deaths (model 2). $\mathrm{PM}_{2.5}$ and $\mathrm{EQI}$ have a negative association with daily new cases as well as daily fatalities from COVID-19. Finally, rainfall has a negative association with daily new cases (model 1 ) and new deaths (model 2). To better understand the impact of environmental and meteorological indicators, we divide the top 10 most affected states into the South and Northwestern regions on the basis that both regions have distinct differentiation in climate (temperature) as well as in environmental pollution emitted from industries and transportation sector. Figure $3 \mathrm{a}$ and $\mathrm{b}$ report the findings through quantile regression. The impact of temperature is positive in both regions but its association decreases at high quantiles for both regions. The impact of humidity is negative at low quantiles but has a marginal positive impact at high quantiles (South region); likewise, humidity has a slight negative impact at high quantiles (Northwestern region). Next, we discuss the findings of environmental pollution indicators and their impact on the COVID-19 outbreak in both regions. $\mathrm{PM}_{2.5}$ has a negative association at middle quantiles for both of the regions, whereas EQI negative correlation at low and high quantiles (South region) and has a positive association especially at middle and high quantiles (Northwestern region). Lastly, we report the impact of rainfall, which is a significant meteorological indicator. Rainfall has a significant negative association at middle and high quantiles for the South region, while has a marginally positive association throughout for the Northwestern region.
Table 3 Empirical results for correlation analysis

\begin{tabular}{llll}
\hline & Climate variables & Daily new cases & Daily new deaths \\
\hline Kendall correlation & Temperature average & $-0.0656^{*}$ & $0.2557^{*}$ \\
& Humidity & $-0.0437^{*}$ & -0.0222 \\
& $\mathrm{PM}_{2.5}$ & 0.0222 & $0.0057^{*}$ \\
& $\mathrm{EQI}$ & $-0.0216^{*}$ & $0.1067^{*}$ \\
Rainfall & $-0.0105^{*}$ & $0.0093^{*}$ \\
& Temperature average & $-0.0976^{*}$ & $0.3796^{*}$ \\
& Humidity & $-0.0662^{*}$ & $-0.0281^{*}$ \\
& PM 2.5 & $0.0333^{*}$ & $0.0095^{*}$ \\
& EQI & -0.0333 & $0.1531^{*}$ \\
& Rainfall & $-0.0194^{*}$ & $0.018^{*}$ \\
\hline
\end{tabular}

$* 5 \%$ level of significance 
Table 4 Log-linear negative binomial analysis

\begin{tabular}{|c|c|c|c|c|c|c|}
\hline \multirow[t]{2}{*}{ Variables } & \multicolumn{2}{|c|}{ Model 1 (daily new cases) } & \multicolumn{4}{|c|}{ Model 2 (daily new deaths) } \\
\hline & Coefficient & $Z$-statistic & $P$ value & Coefficient & $Z$-statistic & $P$ value \\
\hline Temperature & $0.0082 * *$ & 0.8100 & 0.0180 & -0.0081 & -1.3400 & 0.1790 \\
\hline Humidity & $0.0111^{*}$ & 1.6300 & 0.1040 & $-0.0291 * * *$ & -6.7800 & 0.0000 \\
\hline $\mathrm{PM}_{2.5}$ & $0.0191 * *$ & 1.5900 & 0.0110 & $0.0242 * * *$ & 2.9400 & 0.0030 \\
\hline EQI & 0.0126 & 0.1400 & 0.8880 & $1.5528 * * *$ & 14.7600 & 0.0000 \\
\hline Rainfall & $-0.1900 * *$ & -1.9500 & 0.0510 & -0.0233 & -0.1900 & 0.8490 \\
\hline Constant & $6.8516^{* *}$ & 2.3800 & 0.0170 & $-38.3271 * * *$ & -12.0400 & 0.0000 \\
\hline Pseudo $R^{2}$ & 0.1672 & - & - & 0.80 & - & - \\
\hline Further controls & Yes & Yes & Yes & Yes & Yes & Yes \\
\hline
\end{tabular}

Both models are employed by taking covariates as a function of new cases, and daily fatalities

$* p<0.01, * * p<0.05, * * * p<0.001$
Previous research work by Vandini et al. (2013) and Tan et al. (2005) examine the early outbreak of infectious diseases to conclude that temperature is one of the key determinants, with low temperature generally means a higher chance of contracting the virus. Shi et al. (2020) analyzed the impact of climate indicators for 31 provinces in China and detailed that temperature is one of the key factors in the spread of COVID-19. Additionally, the USA being the cultural and financial center of the world oversees very high mobility from domestic as well as abroad to seek economic and business opportunities, which contributed to the widespread outbreak in the USA. Another key indicator is humidity; recent research such as Qi et al. (2020) and Ma et al. (2020) concluded that high temperature and humidity reduce the spread of coronavirus and suggested that the arrival of summer could effectively significantly reduce COVID-19. Another important climate indicator is rainfall. Tosepu et al. (2020) analyzed weather indicators' role in affecting COVID19 in Jakarta, Indonesia, and suggested that higher rainy days influence the spread of COVID-19 cases. Similarly, Lasisi and Eluwole (2021), Șahin (2020), and Ghosh et al. (2020) provided similar findings for the Russian Federation, Turkey, and UK datasets respectively. Our empirical estimates join the strand of recent works Shakoor et al. (2020) and Fareed et al. (2020) for the case of the USA and China.

Another strand of existing literature suggests that long-term exposure to pollution indicators is a significant factor towards higher mortality from COVID-19. Therefore, we included fine particulate matter $\left(\mathrm{PM}_{2.5}\right)$ to examine its impact on the COVID-19 outbreak. The majority of the pre-existing conditions that increase the risk of death for COVID-19 are the same diseases that are affected by long-term exposure to air pollution. In a recent study, Wu et al. (2020) evaluated the bearing of $\mathrm{PM}_{2.5}$ for 300 counties across the USA and discovered that every $1 \mu \mathrm{g} / \mathrm{m}^{3}$ of $\mathrm{PM}_{2.5}$ is linked with a $15 \%$ higher likelihood of getting died due to COVID-19. They further articulated that long-term contact with air pollution means a 20 times higher mortality rate from COVID-19 than any other disease. Likewise, Fareed et al. (2020) also conveyed comparable conclusions for the case of Wuhan China. Ciencewicki and Jaspers (2007) and Sedlmaier et al. (2009) also reported that airborne particulate matter (PM) is responsible for increasingly higher risk of virus diffusion among humans. The environmental quality index serves as a complete environmental indicator for research on human health. Ju et al. (2020) based on investigating the impact of environmental quality towards COVID-19 cases in South Korea concluded that lower environmental quality weakens the human immune system and is the leading contributor in raising the risk of getting infected from COVID-19. In the same way, Dutheil et al. (2020) and Venter et al. (2020) supported similar findings and suggested that higher environmental quality reduces the outbreak of infectious diseases.

\section{Conclusion}

North America, especially the USA, became the COVID-19 epicenter, as the COVID-19 infections had an ever-increasing trend, which is why southern and northwestern states in the USA are facing a record number of infections in recent months. The case example of USA states is a unique scenario as not only these states have higher infectious rates but also a higher mortality rate. This is why in the current research paper, we have analyzed the factors behind new daily cases and new daily deaths to provide a comprehensive analysis of factors associated with the COVID-19 outbreak and federal and state response to the pandemic. Current study investigates the impact of air pollution and meteorological conditions in the transmission of COVID-19 in the ten most affected nations from March 2, 2020, until September 17, 2020. We have investigated the difference between environmental and 
a
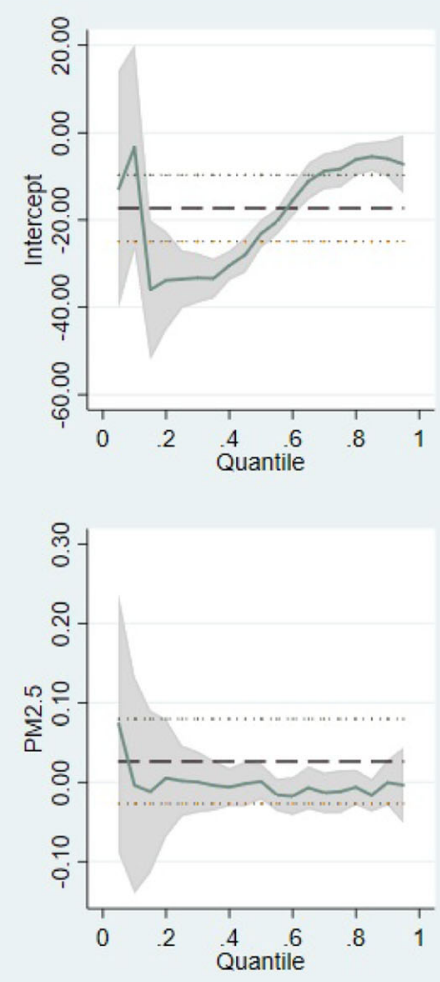
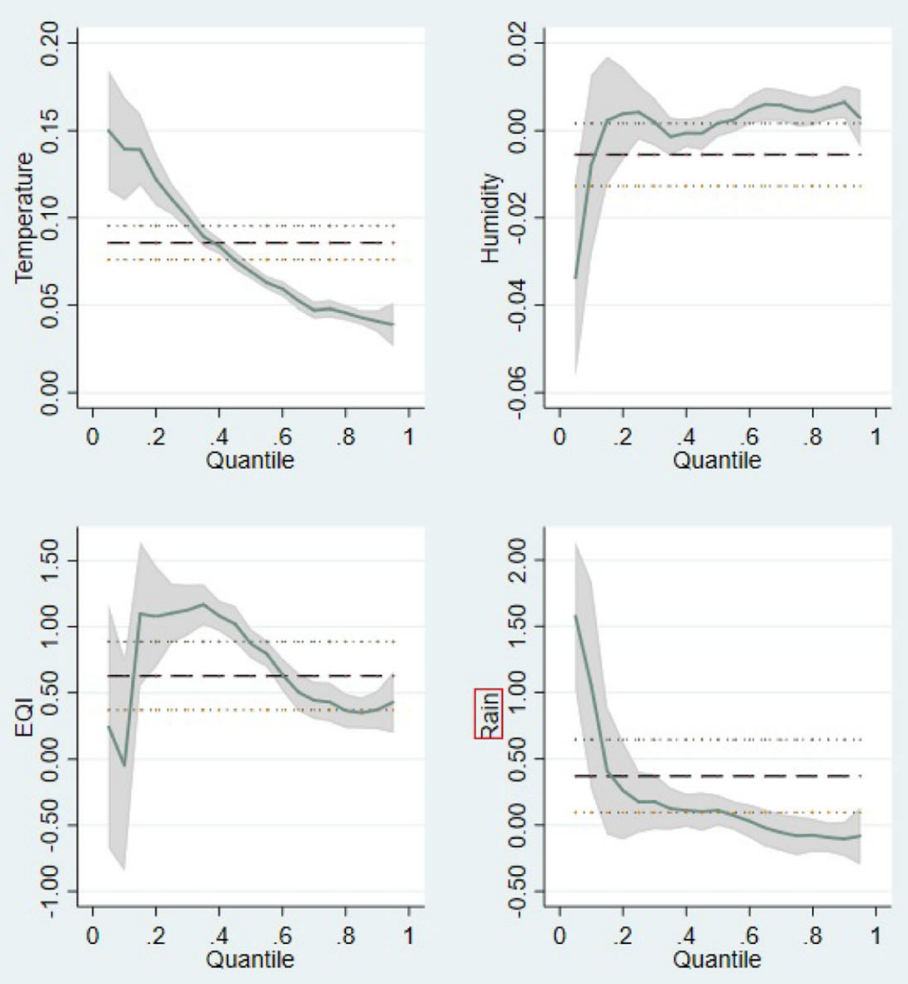

b
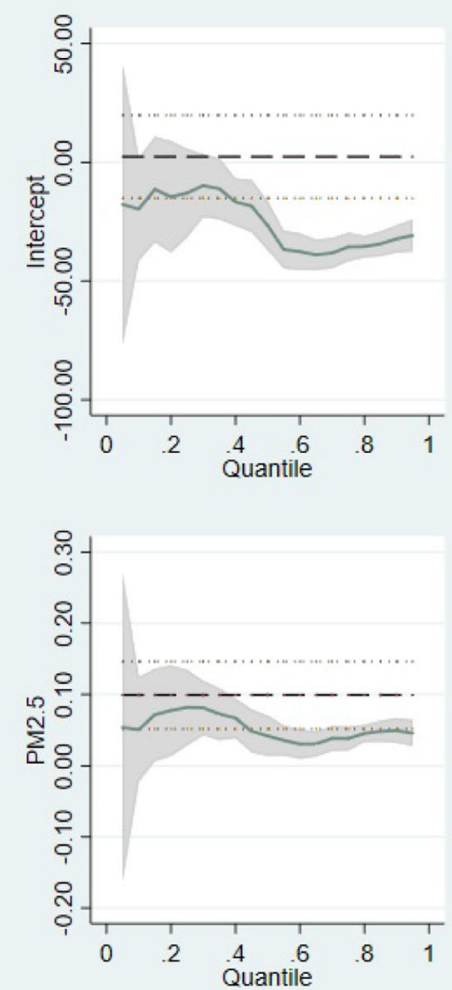
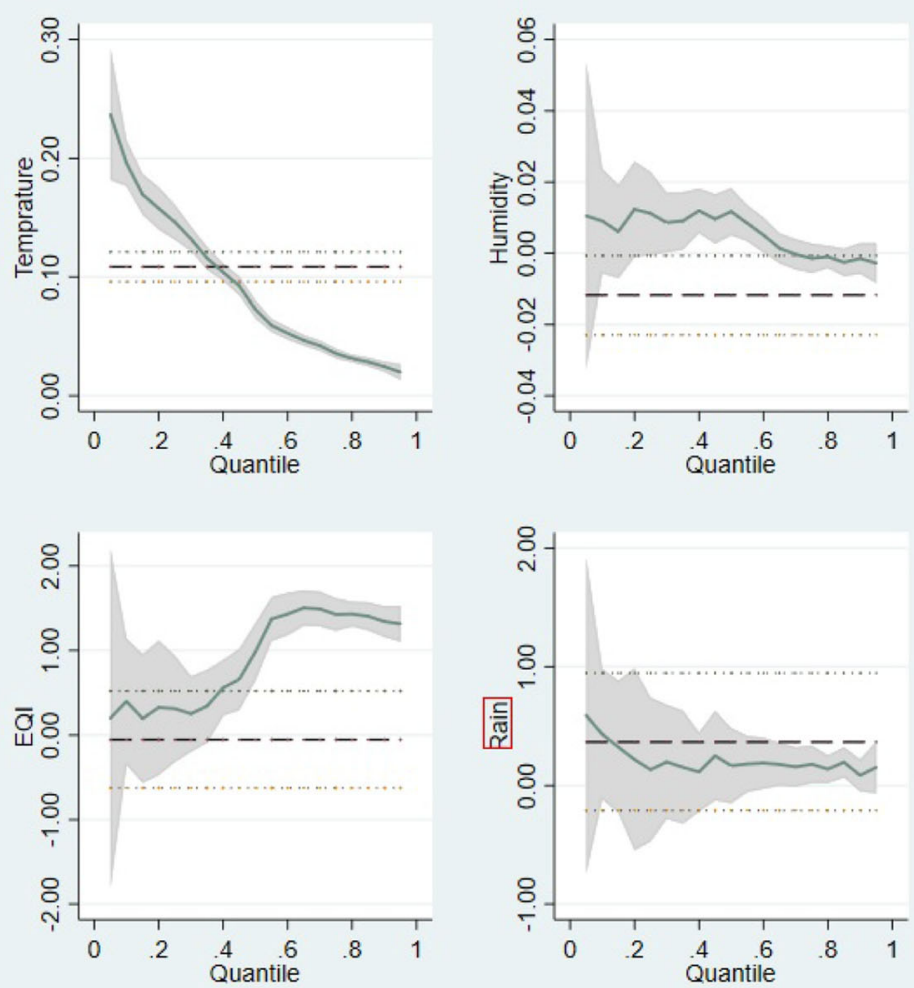

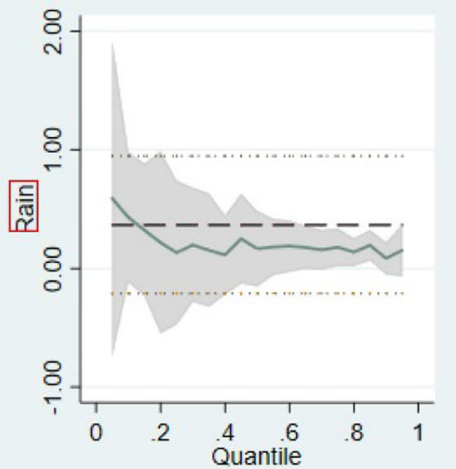

Fig. 3 a Geographical analysis using quantile modelling plot (South region). b Geographical analysis using quantile modelling plot (Northwestern region)

meteorological effects between Southern and Western regions, which has not been done before. Our findings indicate that temperature, humidity, $\mathrm{PM}_{2.5}$, EQI, and rainfall are the 
main determinants of COVID-19 spread in most affected American states.

Our findings indicate that higher environmental and air pollution has contributed significantly in the American states, especially southern states, which rely heavily on fossil fuels, which is responsible for environmental degradation in these states. This is why, as a policy recommendation, USA policymakers need to focus further on environmental pollution and strengthen pandemic response strategies to lower the pandemic threat. Furthermore, as it is evident from recent data that the elderly and children as part of vulnerable age groups have higher susceptibility from COVID-19, a well-managed healthcare infrastructure can offer great assistance in lowering the pandemic threat level. We further provide policy recommendations for state and health officials around the world. We recommend that other countries should take insights from the second-wave of COVID-19 infections in southern USA states and should focus simultaneously on improving the healthcare system as well as introducing long-term pollution control policies to prevent environmental degradation further.

Lastly, although currently there are interesting analytical findings, we offer the following limitations in our research work. First, the current study only offers empirical association of environmental and meteorological conditions in the ten most affected states with data categorized with limited frequency; hence, we encourage further research to analyze meteorological and environmental indicators from panel datasets from emerging and industrial economies to provide more significant insights. Also, the inter-regional analysis would help create a better understanding of COVID-19 as a global pandemic. Finally, future research needs to investigate the impact of urban density, population, virus resistance, and health infrastructure; hence, the evolution of COVID-19 research would guide us about the pandemic, causes, and solutions for future health emergencies.

Author contribution Author contribution is as follows: Bilal, Writing review and editing. Muhammad Farhan Bashir, Writing — original draft, analysis, revision. Khurram Shahzad, Methodology. Bushra Komal, Supervision. Muhammad Adnan Baashir, Project administration. Madiha Bashir, Empirical analysis, Resources. Duojiao Tan, Investigation. Tehreem Fatima, Data curation. Umar Numan, Formal analysis.

Data Availability Research data can be obtained from corresponding author through email

m. $f$, Sh Signature of the corresponding author:

Date of submission: December-29-2020

\section{Declarations}

Ethical approval We certify that the manuscript titled "Environmental quality, climate indicators, and COVID-19 pandemic: insights from top
10 most affected states of USA" (hereinafter referred to as "the paper") has been entirely our original work except otherwise indicated and it does not infringe the copyright of any third party. The submission of the Paper to Environmental Science and Pollution Research implies that the Paper has not been published previously (except in the form of an abstract or as a part of a published lecture or academic thesis), that it is not under consideration for publication elsewhere, that its publication is approved by all authors and that, if accepted, will not be published elsewhere in the same form, in English or any other language, without the written consent of the Publisher. Copyrights for articles published in Environmental Science and Pollution Research are retained by the author(s), with first publication rights granted to Environmental Science and Pollution Research.

Consent to participate We affirm that all authors have participated in the research work and are fully aware of ethical responsibilities.

Consent to publish We affirm that all authors have agreed for submission of the paper to ESPR and are fully aware of ethical responsibilities.

Competing interests The authors have no conflicting interest and are aware of ethical responsibilities.

\section{References}

Alexander C (2008) Market risk analysis, practical financial econometrics, vol 2. John Wiley \& Sons, Hoboken

Allocati N, Petrucci A, Di Giovanni P, Masulli M, Di Ilio C, De Laurenzi V (2016) Bat-man disease transmission: zoonotic pathogens from wildlife reservoirs to human populations. Cell Death Dis 2(1):1-8

Arslan HM, Bilal, Bashir MF (2021) Contemporary research on spillover effects of COVID-19 in stock markets. A systematic and bibliometric review. Sci Forum. https://doi.org/10.3390/ECERPH3-09103

Bashir MF, Ma B, Bilal, Komal B, Bashir MA, Tan D, Bashir M (2020a) Correlation between climate indicators and COVID-19 pandemic in New York, USA. Sci Total Environ 728:138835. https://doi.org/10. 1016/j.scitotenv.2020.138835

Bashir MF, MA BJ, Bilal, Komal B, Bashir MA, Farooq TH, Iqbal N, Bashir B (2020b) Correlation between environmental pollution indicators and COVID-19 pandemic: A brief study in Californian context. Environ Res 187:109652. https://doi.org/10.1016/j.envres. 2020.109652

Bashir MF, Ma B, Shahzad L (2020c) A brief review of socio-economic and environmental impact of COVID-19. Air Qual Atmos Health 13:1403-1409. https://doi.org/10.1007/s11869-020-00894-8

Bashir M, MA B, Bilal et al (2021) Analysis of environmental taxes publications: a bibliometric and systematic literature review. Environ Sci Pollut Res. https://doi.org/10.1007/s11356-02012123-x

Bilal Bashir MF, Shahzad A, Komal B, Bashir MA, Tan D (2021a) Nexus between temperature and COVID-19 pandemic: a meta-analysis. Sci Forum MDPI. https://doi.org/10.3390/ECERPH-3-09098

Bilal, Bashir MF, Komal B, Benghoul M, Bashir MA, Tan D (2021b) Nexus between the COVID-19 dynamics and environmental pollution indicators in South America. Risk Manag Healthcare Policy 14: 67. https://doi.org/10.2147/RMHP.S290153

Burke RM, Midgley CM, Dratch A, Fenstersheib M, Haupt T, Holshue M, Ghinai I, Jarashow MC, Lo J, McPherson TD, Rudman S, Scott S, Hall AJ, Fry AM, Rolfes MA (2020) Active monitoring of persons exposed to patients with confirmed COVID-19 - United States, January-February 2020. MMWR Morb Mortal Wkly Rep 69(9):245-246 
Ciencewicki J, Jaspers I (2007) Air pollution and respiratory viral infection. Inhal Toxicol 19(14):1135-1146

Cucinotta D, Vanelli M (2020) WHO declares COVID-19 a pandemic. Acta Biomed Ateneo Parmense 91(1):157-160

Doğan B, Jebli MB, Shahzad K, Farooq TH, Shahzad U (2020) Investigating the effects of meteorological parameters on COVID19: case study of New Jersey, United States. Environ Res 191: 110148

Dutheil F, Baker JS, Navel V (2020) COVID-19 as a factor influencing air pollution? Environ Pollut 263:114466. https://doi.org/10.1016/j. envpol.2020.114466

Fareed Z, Iqbal N, Shahzad F, Shah SGM, Zulfiqar B, Shahzad K, Hashmi SH, Shahzad U (2020) Co-variance nexus between COVID-19 mortality, humidity, and air quality index in Wuhan, China: new insights from partial and multiple wavelet coherence. Air Qual Atmos Health 13:673-682. https://doi.org/10.1007/ s11869-020-00847-1

Fattorini D, Regoli F (2020) Role of the chronic air pollution levels in the Covid-19 outbreak risk in Italy. Environ Pollut 264:114732

Fofana NK, Latif F, Sarfraz S, Bilal, Bashir MF, Komal B (2020) Fear and agony of the pandemic leading to stress and mental illness: An emerging crisis in the novel coronavirus (COVID-19) outbreak. Psychiatry Res 291:113230

Ge X-Y, Li J-L, Yang X-L, Chmura AA, Zhu G, Epstein JH, Mazet JK, Hu B, Zhang W, Peng C, Zhang YJ, Luo CM, Tan B, Wang N, Zhu Y, Cameri G, Zhang YS, Wang LF, Daszak P, Shi ZL (2013) Isolation and characterization of a bat SARS-like coronavirus that uses the ACE2 receptor. Nature 503(7477):535-538

Ghosh A, Nundy S, Ghosh S, Mallick TK (2020) Study of COVID-19 pandemic in London (UK) from urban context. Cities 106:102928

Hemmes J, Winkler K, Kool S (1962) Virus survival as a seasonal factor in influenza and poliomyelitis. Antonie Van Leeuwenhoek 28(1): 221-233

Huang C, Wang Y, Li X, Ren L, Zhao J, Hu Y, Zhang L, Fan G, Xu J, Gu X, Cheng Z, Yu T, Xia J, Wei Y, Wu W, Xie X, Yin W, Li H, Cao B (2020) Clinical features of patients infected with 2019 novel coronavirus in Wuhan, China. Lancet 395(10223):497-506

Iqbal N, Fareed Z, Shahzad F, He X, Shahzad U, Lina M (2020) The nexus between COVID-19, temperature and exchange rate in Wuhan city: new findings from partial and multiple wavelet coherence. Sci Total Environ 729:138916. https://doi.org/10.1016/j. scitotenv.2020.138916

Ju MJ, Oh J, Choi Y-H (2020) Changes in air pollution levels after COVID-19 outbreak in Korea. Sci Total Environ 750:141521

Jung S-M, Akhmetzhanov AR, Hayashi K, Linton NM, Yang Y, Yuan B, Kobayash T, Kinoshita R, Nishiura H (2020) Real-time estimation of the risk of death from novel coronavirus (COVID-19) infection: inference using exported cases. J Clin Med 9(2):523

Khan S, Nabi G, Han G, Siddique R, Lian S, Shi H, Bashir N, Ali A, Shereen MA (2020) Novel coronavirus: how things are in Wuhan. Clin Microbiol Infect 26(4):399-400

Koenker R, Bassett JR, G. (1978) Regression quantiles. Econometrica 46: $33-50$

Lasisi TT, Eluwole KK (2021) Is the weather-induced COVID-19 spread hypothesis a myth or reality? Evidence from the Russian Federation. Environ Sci Pollut Res 28(4):4840-4844

Ma Y, Zhao Y, Liu J, He X, Wang B, Fu S, Yan J, Niu J, Zhou J, Luo B (2020) Effects of temperature variation and humidity on the death of COVID-19 in Wuhan, China. Sci Total Environ 138226

McDonald SM, Ortaglia A, Bottai M, Supino C (2016) Differential association of cardiorespiratory fitness and central adiposity among U.S. adolescents and adults: a quantile regression approach. Prev Med $88: 1-7$

McMichael AJ, Wilkinson P, Kovats RS, Pattenden S, Hajat S, Armstrong B, Vajanapoom N, Niciu EM, Mahomed H, Kingkeow C, Kosnik M, O'Neil MS, Romieu I, Ramirez-Aguilar M, Barreto
ML, Gouveia N, Nikiforov B (2008) International study of temperature, heat and urban mortality: the 'ISOTHURM'project. Int $\mathrm{J}$ Epidemiol 37(5):1121-1131

Parodi SM, Liu VX (2020) From containment to mitigation of COVID19 in the U.S. JAMA 323(15):1441-1442

Qi H, Xiao S, Shi R, Ward MP, Chen Y, Tu W, Su Q, Wang W, Wang Y, Zhang Z (2020) COVID-19 transmission in Mainland China is associated with temperature and humidity: a time-series analysis. Sci Total Environ 728:138778

Sahin S (2020) Impact of weather on COVID-19 pandemic in Turkey. Sci Total Environ 728:138810

Sardar T, Nadim SS, Rana S, Chattopadhyay J (2020) Assessment of lockdown effect in some states and overall India: a predictive mathematical study on COVID-19 outbreak. Chaos, Solitons Fractals 139:110078

Sedlmaier N, Hoppenheidt K, Krist H, Lehmann S, Lang H, Büttner M (2009) Generation of avian influenza virus (A.I.V.) contaminated fecal fine particulate matter (PM2. 5): genome and infectivity detection and calculation of immission. Vet Microbiol 139(1-2):156-164

Shahzad F, Shahzad U, Fareed Z, Iqbal N, Hashmi SH, Ahmad F (2020) Asymmetric nexus between temperature and COVID-19 in the top ten affected provinces of China: a current application of quantile-onquantile approach. Sci Total Environ 736:139115. https://doi.org/ 10.1016/j.scitotenv.2020.139115

Shakoor A, Chen X, Farooq TH (2020) Fluctuations in environmental pollutants and air quality during the lockdown in the USA and China:two sides of COVID-19 pandemic. Air Qual Atmos Health 13:1335-1342. https://doi.org/10.1007/s11869-020-00888-6

Shi P, Dong Y, Yan H, Li X, Zhao C, Liu W, He M, Tang S, Xi S (2020) The impact of temperature and absolute humidity on the coronavirus disease 2019 (COVID-19) outbreak-evidence from China. medRxiv. https://doi.org/10.1101/2020.03.22.20038919

Sohrabi C, Alsafi Z, O'Neill N, Khan M, Kerwan A, Al-Jabir A, Iosifidis C, Agha R (2020) World Health Organization declares global emergency: A review of the 2019 novel coronavirus (COVID-19). Int J Surg 76:71-76

Tan J, Mu L, Huang J, Yu S, Chen B, Yin J (2005) An initial investigation of the association between the SARS outbreak and weather: with the view of the environmental temperature and its variation. J Epidemiol Community Health 59(3):186-192

Tosepu R, Gunawan J, Effendy DS, Ahmad LOAI, Lestari H, Bahar H, Asfian P (2020) Correlation between weather and Covid-19 pandemic in Jakarta, Indonesia. Sci Total Environ 725:138436

Vandini S, Corvaglia L, Alessandroni R, Aquilano G, Marsico C, Spinelli M, Lanari M, Faldella G (2013) Respiratory syncytial virus infection in infants and correlation with meteorological factors and air pollutants. Ital J Pediatr 39(1):1

Venter ZS, Barton DN, Gundersen V, Figari H (2020) Urban nature in a time of crisis: recreational use of green space increases during the COVID-19 outbreak in Oslo. Norway: SocArXiv. https://doi.org/ 10.31235/osf.io/kbdum

Wang J, Tang K, Feng K, Lv W (2020) High temperature and high humidity reduce the transmission of COVID-19. Available at SSRN 3551767. https://doi.org/10.2139/ssrn.3551767

WHO (2019) Global action plan on physical activity 2018-2030: more active people for a healthier world. World Health Organization. https://www.who.int/ncds/prevention/physical-activity/globalaction-plan-2018-2030/en/

Wu Y, Jing W, Liu J, Ma Q, Yuan J, Wang Y, Du M, Liu M (2020) Effects of temperature and humidity on the daily new cases and new deaths of COVID-19 in 166 countries. Sci Total Environ 729: 139051

Yao TT, Qian JD, Zhu WY, Wang Y, Wang GQ (2020) A systematic review of lopinavir therapy for SARS coronavirus and MERS coronavirus - a possible reference for coronavirus disease-19 treatment option. J Med Virol 92(6):556-563 
Publisher's note Springer Nature remains neutral with regard to jurisdictional claims in published maps and institutional affiliations. 